\title{
THE EFFECT OF THYROTOXICOSIS ON THE ELECTROCARDIOGRAM
}

\author{
BY \\ GERALD SANDLER \\ From the Department of Pharmacology and Therapeutics, University of Sheffield, and Sheffield Royal Infirmary \\ Received June 20, 1958
}

The effect of thyrotoxicosis on the electrocardiogram of the patient, in whom there is no clinical evidence of other types of heart disease and no cardiac arrhythmia, has been a subject of considerable controversy. Joll (1932) maintained that electrocardiographic changes are produced that are pathognomonic of thyrotoxicosis, while other authorities have denied this and have stated that no specific changes occur (McGavack, 1951; White, 1951). A difference of opinion also exists about the occurrence of cardiac hypertrophy in uncomplicated thyrotoxicosis, that is, with no cardiac arrhythmia, congestive failure, or any associated cardiac abnormality, such as coronary artery disease, hypertension, or rheumatic heart disease. Early observers failed to find cardiac enlargement (Lahey, 1930; Hurxthal, 1928), but later reports indicated that clinical evidence of cardiac hypertrophy might be present (Parkinson and Cookson, 1931; Lerman and Means, 1932; Friedberg, 1950).

The aims of the present study are, therefore, to determine whether any specific electrocardiographic abnormalities are produced by thyrotoxicosis, and to investigate the occurrence of left ventricular hypertrophy, assessed on electrocardiographic criteria in uncomplicated cases of hyperthyroidism.

\section{Patients Studied ANd Methods}

Two groups of 50 patients were studied. The first group comprised thyrotoxic patients treated with radioactive iodine, in whom no cardiac arrhythmia and no clinical or radiological evidence of disease of the cardiovascular system was present. All the patients had a normal blood pressure, the diastolic pressure being consistently below $100 \mathrm{~mm}$. of mercury. Electrocardiograms were recorded in these patients, while they were thyrotoxic, and then repeated, when they had become euthyroid following 131I therapy, over intervals of one to seven years after therapy. Euthyroidism was assessed by gain in weight and loss of the symptoms and signs of hyperthyroidism and, where clinical assessment was inconclusive, was confirmed by studies of basal metabolic rate and 131I uptake. The second group, which was a group of controls, consisted of euthyroid patients, in whom there was no clinical or radiological evidence of cardiovascular disease or any other disorder such as pulmonary disease or electrolytic disturbances that might affect the electrocardiogram. This second group was of the same age and sex distribution to the thyrotoxic patients so that any possible differences in electrocardiograms resulting from these two factors were eliminated (Table I). Both the thyrotoxic patients and the controls were selected entirely at random from a much larger pool of patients in each category.

Electrocardiograms were obtained, employing the three standard limb leads, the three unipolar limb leads, aVR, aVL, aVF (Goldberger, 1953), and chest leads V1-V6 (American Heart Association, 1938). The electrocardiographic features analysed were heart rate, the duration and amplitude of the $\mathbf{P}$ wave in lead II, the P-R interval, the duration of the QRS complex and amplitude of $\mathbf{R}$ in lead II, the maximum amplitude of $\mathbf{R}$, the presence of left ventricular hypertrophy assessed by the sum of S in V1 and R in V5 or V6 (Grubschmidt and Sokolow, 1957), the maximum amplitude 
of T, and the corrected Q-T interval. Additional features noted were axis deviation, position of the heart, and abnormalities in the shape and contours of the P wave, QRS complex, and T wave. Standardization was normal $(1 \mathrm{mv} .=1 \mathrm{~cm}$. deflection).

For ease of description of results the thyrotoxic patients will be designated group 1 and the controls group 2. Group 1 was further subdivided into group 1a, consisting of patients before 131I therapy, and group $1 \mathrm{~b}$ comprising the same patients after treatment. A statistical comparison of the electrocardiographic features enumerated above was made between group 1 and group 2 . In addition, since groups $1 \mathrm{a}$ and $1 \mathrm{~b}$ comprised the same patients, the differences in each individual before and after treatment were calculated and analysed statistically. In this way variation between different subjects was eliminated and the changes produced by hyperthyroidism became more apparent.

TABLE I

Age and Sex Distribution in 50 Thyrotoxic Patients in Electrocardiographic Study

\begin{tabular}{c|c|c}
\hline $\begin{array}{c}\text { Age group } \\
\text { (years) }\end{array}$ & \multicolumn{2}{|c}{ No. of patients } \\
\cline { 2 - 3 } & Male & Female \\
\hline $40-49$ & 5 & 19 \\
$50-59$ & 2 & 15 \\
$60-69$ & 2 & 7 \\
\hline Total & 9 & 41 \\
\hline
\end{tabular}

\section{RESULTS}

The results of the analysis are shown in Tables II, III, and IV.

Heart Rate. The mean heart rate in group la was significantly higher than that in both group $1 \mathrm{~b}(\mathrm{p}<0.001)$ and group $2(\mathrm{p}<0.001)$. Furthermore, group $1 \mathrm{~b}$ showed a significantly higher rate than group $2(\mathrm{p}<0.02)$. The mean fall in heart rate in group 1 after ${ }^{131}$ I therapy was also highly significant $(\mathrm{p}<0.001)$.

$P$ Wave. There were no significant differences in duration of the $\mathrm{P}$ wave between groups 1 and 2, nor was there any significant variation between groups $1 \mathrm{a}$ and $1 \mathrm{~b}$. Although the mean

TABLE II

Comparison of Electrocardiographic Features in 50 Thyrotoxic Patients Before and After 131I Therapy AND 50 CONTROLS

\begin{tabular}{|c|c|c|c|c|}
\hline & \multicolumn{3}{|c|}{ Thyrotoxic patients } & \multirow{3}{*}{$\begin{array}{c}\text { Controls } \\
\\
\text { Mean } \\
\pm \text { standard error }\end{array}$} \\
\hline & $\begin{array}{c}\text { Before }{ }^{131} \text { I } \\
\text { therapy }\end{array}$ & $\begin{array}{l}\text { After }{ }^{131} \mathrm{I} \\
\text { therapy }\end{array}$ & \multirow[b]{2}{*}{$\begin{array}{l}\text { Mean difference } \\
\pm \text { standard error }\end{array}$} & \\
\hline & $\begin{array}{c}\text { Mean } \\
\pm \text { standard error }\end{array}$ & $\begin{array}{c}\text { Mean } \\
\pm \text { standard error }\end{array}$ & & \\
\hline $\begin{array}{lcc}\text { Rate/min. } & \ldots & \ldots \\
\text { P wave duration-sec... } & \ldots \\
\text { Height of PII-mv. } & \ldots & \ldots \\
\text { P-R interval-sec. } & \ldots & \ldots \\
\text { QRS duration-sec. } & \ldots & \ldots \\
\text { Height of RII-mv. } & \ldots & \ldots \\
\text { Maximum height of } & \text { R-mv. } \\
\text { Maximum height of } & \text { T-mv. } \\
\text { M-Tc_sec. } & \ldots\end{array}$ & $\begin{array}{l}93 \cdot 9 \pm 2 \cdot 2 \\
0.08 \pm 0.004 \\
1 \cdot 6 \pm 0 \cdot 2 \\
0 \cdot 14 \pm 0.001 \\
0.07 \pm 0.005 \\
11 \cdot 1 \pm 0.6 \\
21 \cdot 3 \pm 0.8 \\
5 \cdot 9 \pm 0.3 \\
0.38 \pm 0.006\end{array}$ & $\begin{array}{l}79 \cdot 6 \pm 1 \cdot 4 \\
0 \cdot 09 \pm 0 \cdot 01 \\
1 \cdot 0 \pm 0 \cdot 2 \\
0 \cdot 14 \pm 0 \cdot 004 \\
0.06 \pm 0.003 \\
8 \cdot 0 \pm 0 \cdot 4 \\
18 \cdot 5 \pm 0 \cdot 8 \\
5 \cdot 8 \pm 0 \cdot 7 \\
0.37 \pm 0.008\end{array}$ & $\begin{array}{c}-14 \cdot 3 \pm 2 \cdot 1 \\
+0.006 \pm 0.003 \\
-0.6 \pm 0.4 \\
+0.004 \pm 0.006 \\
-0.01 \pm 0.003 \\
-3 \cdot 1 \pm 0.48 \\
-2 \cdot 8 \pm 0.8 \\
+0.1 \pm 0.4 \\
-0.008 \pm 0.007\end{array}$ & $\begin{array}{l}74 \cdot 0 \pm 0.9 \\
0.08 \pm 0.003 \\
1 \cdot 2 \pm 0.06 \\
0 \cdot 14 \pm 0.04 \\
0.06 \pm 0.004 \\
6 \cdot 8 \pm 0.4 \\
13 \cdot 7 \pm 0.8 \\
4 \cdot 2 \pm 0.2 \\
0.35 \pm 0.016\end{array}$ \\
\hline
\end{tabular}


TABLE III

InCidence of Abnormalities of P Waves, QRS Complex and T Waves

\begin{tabular}{c|c|c|c}
\hline & \multicolumn{2}{|c|}{50 Thyrotoxic patients } & \multirow{2}{*}{50 Controls } \\
\cline { 2 - 3 } & $\begin{array}{c}\text { Before } \\
\text { 131I therapy }\end{array}$ & $\begin{array}{c}\text { After } \\
\text { 131I therapy }\end{array}$ & \\
\hline P inversion I \\
aVL & 5 & 4 & 3 \\
aVF & 3 & 3 & 7 \\
P notching & 2 & 0 & 0 \\
QRS notching & 4 & 6 & 0 \\
\hline RSR' wave & 5 & 7 & 3 \\
\hline T inversion I & 5 & 4 & 0 \\
III & 1 & 1 & 1 \\
VL & 13 & 21 & 20 \\
VF & 1 & 9 & 6 \\
V1 & 2 & 0 & 1 \\
V6 & 1 & 1 & 0 \\
\hline
\end{tabular}

TABLE IV

Axis Deviation and Cardiac Position in 50 Thyrotoxic Patients and 50 Controls

\begin{tabular}{c|c|c|c}
\hline & \multicolumn{2}{|c|}{ Thyrotoxic patients } & \multirow{2}{*}{ Controls } \\
\cline { 2 - 3 } & $\begin{array}{c}\text { Before } \\
\text { 131 therapy }\end{array}$ & $\begin{array}{c}\text { After } \\
\text { 131I therapy }\end{array}$ & \\
\hline $\begin{array}{c}\text { Axis deviation-left } \\
\text { right }\end{array}$ & 19 & 26 & 21 \\
none & 0 & 0 & 0 \\
Cardiac position-horizontal & 31 & 24 & 29 \\
\hline vertical & 10 & 18 & 14 \\
intermediate & 11 & 7 & 10 \\
\hline
\end{tabular}

amplitude of PII in group 1a exceeded that in group 2, the difference was not significant, and no significant difference was found between groups $1 \mathrm{a}$ and $1 \mathrm{~b}$. P wave inversion in leads III and VL was seen in both groups 1 and 2, but the incidence did not differ significantly (Table III). Inversion of $\mathrm{P}$ in VF occurred in group la only, in two patients. Notching of $\mathbf{P}$ occurred also in group 1 only, and was slightly more frequent after ${ }^{131}$ I therapy than before.

$P-R$ Interval. The mean $\mathrm{P}-\mathrm{R}$ interval was similar in groups 1 and 2 and was within normal limits. Although there was a mean increase of 0.004 sec. in the thyrotoxic patients after 131 I therapy, the change was not significant.

QRS Complex. There was no significant difference in mean duration of the QRS complex between the thyrotoxic patients in group 1a and the normal subjects in group 2; in both these groups the values were within normal limits. However, when the measurements were compared on an individual basis in the same patients in groups $1 \mathrm{a}$ and $1 \mathrm{~b}$, a slight, but significant, fall became apparent after treatment of the thyrotoxicosis $(\mathrm{p}<0.01)$. The mean amplitude of RII and the mean maximum amplitude of $R$ in group 1a were significantly higher than those in group $2(p<0 \cdot 001)$, and there was also a significant fall in amplitude in group 1 following ${ }^{131}$ I therapy $(p<0 \cdot 001)$. Furthermore, group $1 \mathrm{~b}$ showed a significantly higher value than group $2(\mathrm{p}<0.01)$. The incidence of abnormalities of the QRS complex, either notching or fully developed RSR' complexes, was higher in group 1 than in group 2, but not significantly so. 
Left Ventricular Hypertrophy. The criterion adopted for assessment of left ventricular hypertrophy was that considered the most reliable in middle-aged patients by Grubschmidt and Sokolow (1957) and Sokolow and Lyon (1949): it was judged to be present, when the sum of S in V1 plus R in V5 or V6 (whichever is the larger) was in excess of $35 \mathrm{~mm}$. in the standard $1 \mathrm{~cm} .-1 \mathrm{mv}$. electrocardiogram. On this basis none of the normal controls in group 2 had left ventricular hypertrophy. It was, however, present in 14 patients in group 1a and disappeared in nine of these after 131I therapy. There was no significant difference in the mean interval of time after therapy, in the five patients in whom hypertrophy persisted, 32.4 months, and in the nine patients in whom it disappeared, 31.3 months. In addition hypertrophy became apparent after treatment in three other patients in group $1 b$ who had not shown it, while they were hyperthyroid. They had not been unduly long in becoming euthyroid after therapy and in this respect did not differ from the remaining patients in group $1 \mathrm{~b}$, in whom hypertrophy did not develop.

The importance of a number of clinical factors in the production of left ventricular hypertrophy in the electrocardiogram was assessed by making a detailed comparison between all patients with and without hypertrophy. These factors included age, sex, systolic and diastolic blood pressure, duration of thyrotoxicosis, and severity of thyrotoxicosis as assessed by the 4-hour uptake of 131I (Goodwin et al., 1951). Furthermore, in view of the relationship between high voltage præcordial leads and thinness of chest wall, the mean weights of patients with and without hypertrophy were compared to avoid any possibility of obtaining a false positive result. However, no significant differences were found in any of these factors, either between hyperthyroid patients with and without hypertrophy, or between the hyperthyroid patients with persistent hypertrophy and those in whom hypertrophy disappeared after treatment.

$T$ Wave. No significant differences in the mean maximum amplitude of the $T$ wave were found between group 1 and group 2, and between groups $1 \mathrm{a}$ and $1 \mathrm{~b}$. Inversion of the $\mathrm{T}$ waves occurred in all three groups, but the incidence did not vary significantly. Inversion was most frequent in aVL in group $1 \mathrm{a}$ and in lead III in groups $1 \mathrm{~b}$ and 2.

$Q-T c$. The mean Q-T interval corrected for heart rate (Taran and Szilagyi, 1947) did not differ significantly in the three groups and was within normal limits.

Axis Deviation and Cardiac Position. There was no significant difference in the incidence of left axis deviation between the three groups (Table IV). No patient in any group showed right axis deviation. The electrical position of the heart was determined according to the criteria published by Goldberger (1953). The incidence of horizontal, vertical, and intermediate hearts did not differ significantly in groups 1 and 2, neither were there any significant differences in electrical position between group la and group $1 \mathrm{~b}$ (Table IV).

\section{DISCUSSION}

Sinus tachycardia is the usual finding in thyrotoxicosis and is proportional to the increase in basal metabolic rate (Yates, 1932). It was found in the present series and, although treatment with 131I resulted in a significant fall in heart rate, the mean heart rate was still significantly higher in the treated thyrotoxic patients than in the controls. This may be associated with a persistently increased cardiac output, even when euthyroidism has been attained. Hyperthyroidism is associated with extensive peripheral vasodilatation and an increased cardiac output (Myers et al., 1950; Bishop et al., 1955). An increased cardiac output resulting from extensive or large arterio-venous shunts does not always return to normal levels after closure of the fistulae (Cohen et al., 1949).

Increased duration of the $P$ wave has been reported in thyrotoxicosis (Gordan et al., 1944) but this has not been confirmed in this series. Increased amplitude of $\mathbf{P}$ waves has also been found (Parkinson and Cookson, 1931) and especially in leads II and III (Goodall, 1920; Smith and Colvin, 1927). Although PII was tall it did not exceed the normal upper limit of $3 \mathrm{~mm}$. in this lead (White, 1951) and did not differ significantly from the controls. The increased amplitude in the thyrotoxic patients may be the result of the increased cardiac output occurring in thyrotoxicosis, as similar increases can occur with exercise alone (White, 1951). Notching of $\mathbf{P}$ waves was confined to 
thyrotoxic patients and persisted after ${ }^{131}$ I therapy. Gordan et al. (1944) found similar notching in thyrotoxicosis.

The P-R interval has been found to be prolonged in hyperthyroidism by a number of observers (Krumbhaar, 1918; Willius et al., 1923; Damashek, 1924; Goodall and Rogers, 1927). In the present series the $\mathbf{P}-\mathbf{R}$ interval was identical in groups 1 and 2 , and well within normal limits. This interval has been found to vary with age and heart rate (Ashman and Hull, 1937) and the prolongation described by these earlier observers may have resulted from omission to make allowance for these two factors.

Although there was no significant increase in the duration of the QRS complex in the thyrotoxic patients compared with the controls, there was a significant fall in duration in the thyrotoxic patients after 131I therapy, suggesting that thyrotoxicosis does produce an increased duration of the QRS complex. Both RII and the maximum amplitude of $\mathrm{R}$ were significantly increased in the thyrotoxic patients, the greatest amplitude of $R$ being found most commonly in V4 and V5. A slight increase in the amplitude of RII was described by Joll (1932), but in the same year Don and Langley (1932) found no constant relationship between the amplitude of $\mathrm{R}$ and the basal metabolic rate in thyrotoxicosis.

In 14 thyrotoxic patients there was electrocardiographic evidence of left ventricular hypertrophy. The high voltage præcordial leads could not be regarded as false positives due to excessive thinness in the thyrotoxic patients, as their mean weight did not differ significantly from the 36 thyrotoxic patients not showing hypertrophy. Neither was the incidence of hypertrophy attributable to the effect of greater age. Cardiomegaly in thyrotoxicosis has been considered exceptional (Smith and Colvin, 1927; Hurxthal, 1928; Lahey, 1930). When it has been found, associated cardiovascular disease, such as coronary artery disease, hypertension, or rheumatic heart disease, has usually been also present (Hurxthal et al., 1930; Gotta, 1938; McPhedran, 1942; Levene and Miller, 1942). In all these studies, however, assessment of cardiac enlargement and hypertrophy has been made mainly on clinical and radiological grounds. In the present series the heart size was normal clinically and radiologically in all these patients and careful clinical examination revealed no possible cause for cardiac hypertrophy other than thyrotoxicosis. In these patients, therefore, the electrocardiogram appears a more sensitive index of left ventricular hypertrophy than the other methods of examination. When severe cardiac involvement, such as congestive failure, occurs in thyrotoxicosis in the absence of associated heart disease, it has been found that intensity of hyperthyroidism may be a contributory factor (Hurxthal, 1928; Andrus, 1929), and also that duration of thyrotoxicosis is an important factor in producing cardiac complications (Griswold and Keating, 1949; Friedberg, 1950). Both of these factors were considered in relation to the incidence and persistence after treatment of cardiac hypertrophy, but no correlation could be found. In 5 of these 14 patients left ventricular hypertrophy appeared to be irreversible over periods ranging from 17 to 70 months after ${ }^{131}$ I therapy, and its persistence was not related to a shorter follow-up period in these patients compared with the nine patients in whom the hypertrophy disappeared. Similarly a persistence of cardiomegaly, assessed mainly on radiological grounds in 13 thyrotoxic patients after ${ }^{131}$ I therapy, has been found by Sandler and Wilson (1958). They were patients, in whom cardiomegaly was the sole manifestation of cardiac involvement, thereby resembling the patients in the present series, in whom the electrocardiogram alone gave evidence of left ventricular hypertrophy.

In view of the flattening or inversion of the $T$ waves occurring so frequently in myxœdema, it might be expected that increased amplitude of $T$ waves would occur in thyrotoxicosis. In this series, however, no significant changes in $T$ wave amplitude occurred in the thyrotoxic patients and similar conclusions have been reported by White (1951). T wave inversion was present in one or other lead in over 50 per cent of the thyrotoxic patients, but occurred in an even greater percentage of the controls. Willius et al. (1923), found that the T wave was often low or inverted in thyrotoxicosis. Gordan et al. (1944) found T wave abnormalities consisting of low amplitude, diphasic or abnormally shaped waves, in 19 per cent of 121 thyrotoxic patients, but in the majority of these 
patients the abnormalities disappeared after treatment of the thyrotoxicosis. In the present series the $T$ wave inversion has increased in incidence in the thyrotoxic patients after ${ }^{131}$ I therapy.

The Q-T interval, corrected for heart rate, may be prolonged in rheumatic and other forms of myocarditis, and it has been claimed that thyrotoxicosis produces an interstitial myocarditis (Fahr, 1916; Wilson, 1923; Goodall and Rogers, 1927; Lewis, 1932). This interval was not significantly altered in the thyrotoxic patients and was within normal limits.

\section{SUMMARY}

A comparison was made between the electrocardiograms of 50 patients with uncomplicated thyrotoxicosis before and after radioactive iodine therapy and of 50 euthyroid patients of identical age and sex distribution free from any cardiovascular disturbances.

Significant electrocardiographic changes found in the thyrotoxic patients comprised an increased heart rate, an increased duration of the QRS complex, and an increased amplitude of RII and maximum amplitude of $\mathbf{R}$. There was no significant alteration of duration of the $\mathbf{P}$ wave, amplitude of PII, P-R interval, maximum amplitude of the $\mathrm{T}$ wave, or the corrected $\mathrm{Q}-\mathrm{T}$ interval.

Left ventricular hypertrophy, judged to be present when the sum of S in V1 plus R in V5 or V6 was in excess of $35 \mathrm{~mm}$., was found in 14 hyperthyroid patients before ${ }^{131}$ I therapy and disappeared in 9 after therapy. Age and weight of the patient and duration and severity of the thyrotoxicosis were not related to the incidence or persistance of hypertrophy.

It is concluded that thyrotoxicosis alone can produce left ventricular hypertrophy and an increased duration of the QRS complex, but does not otherwise cause any specific or pathognomonic changes in the electrocardiogram.

I would like to thank Professor G. M. Wilson for much helpful advice and criticism in the preparation of this paper.

\section{REFERENCES}

American Heart Association (1938). Amer. Heart J., 15, 235.

Andrus, E. C. (1929). New York St. J. Med., 29, 661.

Ashman, R., and Hull, E. (1937). Essentials of Electrocardiography. Macmillan, New York.

Bishop, J. M., Donald, K. W., and Wade, O. L. (1955). Clin. Sci., 14, 329.

Cohen, S. M., Edholm, O. G., Howarth, S., McMichael, J., and Sharpey-Schafer, E. P. (1949). Clin. Sci., 7, 35.

Damashek, W. (1924). Boston med. surg. J., 190, 487.

Don, C. S., and Langley, G. J. (1932). Quart. J. Med., 1, 9.

Fahr, T. (1916). Zbl. allg. Path. path. Anat., 27, 1.

Friedberg, C. K. (1950). Diseases of the Heart. 1st ed. Saunders, Philadelphia.

Goldberger, E. (1953). Unipolar Lead Electrocardiography. 3rd ed. Henry Kimpton, London.

Goodall, J. S. (1920). Practitioner, 105, 37.

- and Rogers, L. (1927). Lancet, 1, 486.

Goodwin, J. F., Macgregor, A. G., Miller, H., and Wayne, E. J. (1951). Quart. J. Med., 20, 353.

Gordan, G., Soley, M. H., and Chamberlain, F. L. (1944). Arch. intern. Med., 73, 148.

Gotta, H. (1938). Arch. intern. Med., 61, 860.

Griswold, D., and Keating, J. H., Jr. (1949). Amer. Heart J., 38, 813.

Grubschmidt, H. A., and Sokolow, M. (1957). Amer. Heart J., 54, 689.

Hurxthal, L. M. (1928). Amer. Heart J., 4, 103.

, Menard, O. J., and Bogan, M. E. (1930). Amer. J. med. Sci., 180, 772.

Joll, C. A. (1932). Diseases of the Thyroid Gland. Heinemann, London.

Krumbhaar, E. B. (1918). Amer. J. med. Sci., 155, 175.

Lahey, F. H. (1930). Surg. Gynec. Obstet., 50, 139.

Lerman, J., and Means, J. H. (1932). Amer. Heart J., 8, 55.

Levene, G., and Miller, L. C. (1942). Radiology, 38, 573.

Lewis, W. (1932). Amer. J. Path., 8, 255.

McGavack, T. H. (1951). The Thyroid, p. 35. Henry Kimpton, London.

McPhedran, H. (1942). Canad. med. Ass. J., 46, 471.

Myers, J. D., Brannon, E. S., and Holland, B. C. (1950). J. clin. Invest., 29, 1069.

Parkinson, J., and Cookson, H. (1931). Quart. J. Med., 24, 499.

Sandler, G., and Wilson, G. M. (1958). Quart. J. Med., to be published.

Smith, F. J., and Colvin, L. T. (1927). Ann. clin. Med., 5, 616.

Sokolow, M., and Lyon, T. P. (1949). Amer. Heart J., 37, 161.

Taran, L. M., and Szilagyi, N. (1947). Amer. Heart J., 33, 14.

White, P. D. (1951). Heart Disease. 4th ed. Macmillan, New York.

Willius, F. A., Boothby, W. M., and Wilson, L. B. (1923). Med. Clin. N. Amer., 7, 189.

Wilson, L. D. (1923). Trans. Ass. Amer. Physiol., 38, 144.

Yates, W. M. (1932). Amer. Heart J., 8, 1. 